\title{
Brokers of relevance in National Park Service urban collaborative networks
}

\author{
Elizabeth E. Perry ${ }^{1}$, Daniel H. Krymkowski ${ }^{2}$ and Robert E. Manning ${ }^{3}$
}

\begin{abstract}
Conservation agencies are increasingly tasked with furthering their relevance with the public, in addition to protecting the natural and cultural resources in their care. Relevance is imperative to sustaining and diversifying invested stewards of these resources and support for their continued protection. Collaborative networks among organizations sharing similar goals and diverse audiences can facilitate relevance by connecting conservation agencies to new partners, ideas, and audiences. In particular, brokers, or organizations connecting other organizations in these networks, may be well positioned to enhance relevance. Brokers' diverse network connections may give them a unique function with regard to relevance. Their different roles connecting within, between, or among groups may also illuminate where relevance connections exist and can be forged. In this investigation, we examined different brokerage roles in U.S. National Park Service (NPS) collaborative networks and their potential implications for enhancing NPS relevance. The NPS' mission is centered on the dual goals of relevance and resource conservation. Recognizing the need for enhanced relevance and related supportive collaborative networks, the NPS recently established its Urban Agenda, specifically aimed toward building "relevancy for all Americans" and a "culture of collaboration." We conducted a quantitative network analysis in three sites with NPS Urban Agenda investment: Detroit, Tucson, and Boston. We compared the sites' current to desired networks, i.e., present to potential networks, to determine which brokerage roles have more or less opportunity for growth and what broker-specific measures and broader network attributes may mean for collaboratively striving toward greater NPS relevance. Our findings suggest that specific organizational categories may be current brokers of relevance as well as potential leverage points for further diversification of partners, ideas, and audiences. In examining these organizational categories and brokerage roles, the NPS and other conservation agencies can strategically, and with foresight, emphasize certain areas for relevance-related networking development.
\end{abstract}

Key Words: Boston; brokerage; density; Detroit; G\&F brokerage; Gould and Fernandez brokerage; National Park Service; relevance; social network analysis; Tucson; urban

\section{INTRODUCTION}

Conservation and relevance in the U.S. National Park Service The National Park Service (NPS), a century-old institution, centers its work on a mission with the dual focus of preserving the U.S.'s nationally significant stories and scenery and engaging people in perpetuity in these sites. This mission states that the agency "preserves unimpaired the natural and cultural resources and values of the national park system for the enjoyment, education, and inspiration of this and future generations" (U.S. Congress 1916). In this mission, conservation is explicit in the first section and relevance is implied in the second.

"Relevance" is an ideal, elusive state. Despite this seemingly abstract character, it is an imperative goal for conservation agencies such as the NPS (Diamant 2000, Mitchell et al. 2006, Ferreira 2012, Jarvis 2012). At the core of this concept are two managerially focused tenets. First, relevance is a process of identifying common goals with a target audience and working toward these goals to enhance the agency's relevance with that audience (Gorayska and Lindsay 1993). Second, working toward these goals entails engaging in inclusive practices that broaden and deepen the agency's resonance, usefulness, or applicability to the audience's experiences and quality of life (Henderson and Walker 2014). As such, relevance is vital to realizing the democratic nature of the U.S. park system. To foster lasting engagements with generations of conservation stewards, the NPS needs to continue work on building relevance.
One context in which they have clearly stated and worked toward this relevance need is in urban areas with local populations. To better connect local populations with the NPS, the agency embarked on an Urban Agenda in 2015 (NPS Stewardship Institute 2015). This Agenda, a centennial effort, aims toward three interrelated goals. Two are pertinent to this investigation. The overarching goal is "Relevancy for all Americans," or finding ways in which the NPS may be a more useful and integrated component of people's daily lives. A second goal, "Building a culture of collaboration," is a process by which to strive for relevance. In this, the NPS seeks to expand its partnership networks so as to find common areas of relevance goal definition with other organizations and thus, with their constituents. The NPS has used a typology as a means of considering the organizational landscape and discerning who may be a valuable connection for relevance efforts. This typology has eight categories: Economic Vitality, Educational Opportunities, Health, Historic Preservation, Outdoor Recreation, Sustainability, Urban Design, and Youth (Table 1). It has been used as an efficient means to assess NPS involvements across a range of organizations and examine where there are areas of relative abundance and paucity of relationships.

The Urban Agenda, with associated resources for its success, was piloted in 10 diverse cities in 2015-2017. In each, an urban liaison, the NPS Urban Fellow, was hired in summer 2015 as a convener and promoter of NPS urban relevance networks and efforts. This person was considered a networking leader (Eglene et al. 2007) and hired in part because of this capacity. An affiliated NPS Site

${ }^{1}$ Department of Parks, Recreation, and Tourism Management, Clemson University, ${ }^{2}$ Department of Sociology, University of Vermont, ${ }^{3}$ Rubenstein School of Environment and Natural Resources, University of Vermont 
Table 1. National Park Service Urban Agenda typology of organizational categories, with descriptions and examples of each category.

\begin{tabular}{|c|c|c|}
\hline Organizational category & $\begin{array}{l}\text { Description: } \\
\text { Organizations associated with... }\end{array}$ & Examples \\
\hline $\begin{array}{l}\text { Cultural Resources (formerly Historic } \\
\text { Preservation) } \\
\text { Diversity Inclusion (additional category) }\end{array}$ & $\begin{array}{l}\text { The preservation of historic sites, cultural artifacts, and } \\
\text { related social narratives } \\
\text { Specific minority communities }\end{array}$ & $\begin{array}{l}\text { Historic societies } \\
\text { Re-enactment commemorations } \\
\text { Hispanic/Latinx groups } \\
\text { LGBTQIA+ groups }\end{array}$ \\
\hline Economic Vitality & $\begin{array}{l}\text { Developing, sustaining, and promoting business } \\
\text { opportunities and city attractions }\end{array}$ & $\begin{array}{l}\text { Neighborhood associations } \\
\text { City vitality planning departments }\end{array}$ \\
\hline Educational Opportunities & $\begin{array}{l}\text { Traditional school-age education and lifelong continuing } \\
\text { education }\end{array}$ & $\begin{array}{l}\text { Universities } \\
\text { Adult education }\end{array}$ \\
\hline Health & Physical and mental well-being & $\begin{array}{l}\text { Hospitals } \\
\text { Nursing associations }\end{array}$ \\
\hline Outdoor Recreation & $\begin{array}{l}\text { Providing access to and advocacy for opportunities for } \\
\text { outdoor active leisure pursuits }\end{array}$ & $\begin{array}{l}\text { Parks and recreation departments } \\
\text { Nonprofit access associations }\end{array}$ \\
\hline Sustainability & $\begin{array}{l}\text { Environmental resilience and environmental causes as part } \\
\text { of a greater sustainable future }\end{array}$ & $\begin{array}{l}\text { Natural resource management departments } \\
\text { Advocacy groups }\end{array}$ \\
\hline Urban Design & $\begin{array}{l}\text { Architecture and intelligent design and revitalization of } \\
\text { city structures }\end{array}$ & $\begin{array}{l}\text { Architecture firms } \\
\text { Development strategists }\end{array}$ \\
\hline Youth & Opportunities for local residents under 18 years & $\begin{array}{l}\text { Summer camps } \\
\text { After-school/affinity interest clubs }\end{array}$ \\
\hline
\end{tabular}

Host (the "local champion" of the NPS urban effort) supported the Urban Fellow's work and together they were knowledgeable about the city characteristics, NPS presence, and key contacts. The Urban Fellow and Site Host were challenged to address the issue of relevance at least partially through building networks among these key contacts. Thus, the Urban Agenda's emphasis on collaborative organizational networks was imperative to broadening pathways toward relevance with a large local population of diverse stewards.

This investigation, therefore, examines attributes of current collaborative networks, and areas of desired growth that may promote or constrain relevance. In particular, types of brokers within these networks are investigated as a managerially identifiable and actionable area for enhancing relevance efforts. A broker is an organization that connects two other organizations, those that make "friend-of-a-friend" relationships across the network. Connections between similar organizations are bonds and connections between dissimilar organizations are bridges. Brokerage can be particularly helpful in identifying where relevance can be enhanced by facilitating both numerous and varied bonds and bridges to reach underserved and potentially new audiences. Although set in the context of three urban NPS sites, the methods and findings of this investigation transcend the agency's particular dual mission of conservation and relevance. We expect that they extend to conservation agencies concerned with building relationships that foster connections to a greater breadth and depth of stewards. This investigation details pathways to both investigate and strengthen these relationships for relevance.

\section{Relevance as a collaborative network goal}

Collaborative networks that share a common relevance goal may be well positioned to incorporate new, diverse, or more widespread expressions of relevance (Vangen and Huxham 2012, Page et al. 2015). These networks have increasingly been used as a means to steward natural and cultural resources, especially in parks and protected areas (e.g., Hamin 2001, Holman 2008,
Belaire et al. 2011, Kaźmierczak 2013, Enqvist et al. 2014). Correspondingly, research on governance of and resource conservation in these park-centric collaborative networks has gained traction because probing network structure can often provide more detail on adaptive management and knowledge exchange among the diverse stakeholders joined by a resource concern (Bodin et al. 2006, Crona and Bodin 2006, Crona and Hubacek 2010, Bodin and Prell 2011).

The use of network analysis methods assists in quantitatively examining these collaborative structures and their attributes (Knoke and Yang 2008, Butts 2008, Giuffre 2013, Harris 2014) but do not yet appear to have been applied to relevance-centered networks. Sandström and Rova (2010), for example, found that low density networks (those with few connections among members) around fishery conservation areas in Sweden inhibit management goal definition and, ultimately, protected area legitimacy. Other work on marine protected areas in Chile found similar low levels of cohesion, centralization, and density that necessitated the inclusion of additional bridging stakeholders in the network (Francisco Cárcamo et al. 2014). In Swiss park collaboratives, Hirschi (2010) found that network structure changed over time to strengthen vertical (e.g., chain-ofcommand) collaborations while horizontal (e.g., peer-to-peer) collaborations remained stagnant. Romolini et al. (2013) contributed to understanding on how environment (geographic location and canopy cover) may influence urban natural resource stewardship networks. Informal structures are important as well, as Prell et al. (2010) found that organizations sharing similar perceptions about park management in the UK also share stronger relationships within the network, and Calvet-Mir et al. (2015) found that low density and in-degree centrality may relate to low trust levels in the park participatory process in Catalonia. Studies such as these have value for informing managers about who should be included in networks of park governance processes and discussions, as well as what barriers to inclusion and messaging might be. 
Table 2. Gould and Fernandez (G\&F) brokerage role descriptions.

\begin{tabular}{|c|c|c|c|c|}
\hline \multirow[t]{2}{*}{ G\&F brokerage role } & \multirow[t]{2}{*}{ Role description } & \multicolumn{3}{|c|}{ Triad composition } \\
\hline & & Source & Broker & Recipient \\
\hline Coordinator & All members belong to the same category & A & $\rightarrow \mathrm{A} \rightarrow$ & A \\
\hline Gatekeeper & Source belongs to a different category & $\mathrm{B}$ & $\rightarrow \mathrm{A} \rightarrow$ & A \\
\hline Representative & Recipient belongs to a different category & A & $\rightarrow \mathrm{A} \rightarrow$ & $\mathrm{B}$ \\
\hline Consultant & Broker belongs to a different category & $\mathrm{B}$ & $\rightarrow \mathrm{A} \rightarrow$ & $\mathrm{B}$ \\
\hline Liaison & All members belong to different categories & $\mathrm{B}$ & $\rightarrow \mathrm{A} \rightarrow$ & $\mathrm{C}$ \\
\hline
\end{tabular}

What has been lesser detailed, however, is how park-related collaborative networks engage each other to promote shared relevance goals. Shared stewardship of a resource has relied at least partially on the ability to share information. However, linking stakeholders to promote the relevance of these resources to people's everyday lives may be equally important. For example, NPS park "friends groups," nonprofit organizations that assist public land management with activities such as fundraising and volunteering, and youth-focused organizations, e.g., schools, YMCA, and science centers, have coordinated efforts to develop park-based engagement and leadership opportunities for youth (McCown et al. 2011, 2012). NPS National Heritage Areas, public-private partnerships to integrate environmental, community, and economic objectives at a regional scale, have also coalesced around issues of relevance with these trifold objectives (Laven et al. 2010). These networks may be able to diversify and amplify conservation and engagement messages about the resource or place of concern as well as further embed the managing agency into the community. Without tangible and multifaceted connections, these places may lose the support of the public and ultimately may cease to exist (Jarvis 2012). Thus, collaborative networks centered on the goal of relevance instead of the process of governance is a promising area for research. Because actual change in collaborative networks can only be detected in hindsight, when relevance may have been diminished or extinguished, there is benefit to assessing what current versus future networks may look like. However, studies proactively assessing network structures for enhancing relevance appear sparse.

\section{Brokers' role in facilitating collaborative network relevance}

Relationships among members of a collaborative network can potentially facilitate or hinder relevance. In particular, brokers, or the intermediaries who reach across the network to connect otherwise unconnected members (Burt 1997, Stovel and Shaw 2012), may have a role in promoting relevance. Examining the role of brokers more precisely may lend nuance to understanding this relationship. Brokers hold the ability to facilitate a range of bonds (relationships within their group) and bridges (relationships to other groups; Stovel and Shaw 2012). Their ability to connect different types and scales of collaborators for resource management issues is important but sometimes lacking (Ernstson et al. 2010). For example, a collection of green spaces in Stockholm lacking midscale managers to transcend geographical differences could have more effectual and inclusive governance processes if scale-crossing brokers were able to navigate these differences (Ernstson et al. 2010).
Although brokerage is defined at the individual relationship level (Totterdell et al. 2008), summarizing brokers as a group has provided insight in other contexts (Stovel and Shaw 2012, Long et al. 2013). Manring (2007) contends that brokers are groups that, among other capacities, may facilitate, coordinate, and promote entrepreneurial relationships within a network and Stovel and Shaw (2012) promote brokers as the group central to shaping social integration processes. Although some studies have measured brokerage indirectly (Aviv et al. 2005, Faust 2010, Laven et al. 2010, Scott 2013, Spiro et al. 2013), brokers as a collection of members require a more explicit focus (Stovel and Shaw 2012, Everett and Valente 2016).

Gould and Fernandez (1989) offer a typology of the five possible types of positions brokers can have based on category membership (Table 2), known as G\&F brokerage roles. Given the categorization of members into groups by a particular attribute (e.g., organization, zip code, supervisory status), G\&F brokerage roles can identify the prevalence of brokers facilitating the five possible combinations of bonds and bridges within the triad's three members (the source, broker, and recipient). Coordinators facilitate two bonds; the source, broker, and recipient are all similar to each other. Gatekeepers and Representatives facilitate one bond and one bridge; either the source and broker are similar to each other and dissimilar from the recipient (Gatekeepers) or the recipient and broker are similar to each other and dissimilar from the source (Representatives). Consultants and Liaisons facilitate two bridges; either the source and recipient are similar to each other but dissimilar from the broker (Consultants) or the source, broker, and recipient are all dissimilar from each other (Liaisons). In this manner, G\&F brokerage roles may assist in identifying brokers who facilitate the connections necessary for relevance within and across categories of members in a collaborative network. G\&F brokerage roles have been examined in contexts as diverse as motivations for building relationships across Jewish-, Arab-, and Druze-Israeli communities (Kalish 2008); the influence of the European Commission on multiscale governance interactions (Borrás 2007); and comic book industry publishing relationships (Boari and Riboldazzi 2014). Yet, they appear to have drawn less focus in natural resource or park management. Inherent in these studies' findings is that brokers have a crucial role in facilitating innovation and connections among network members and categories. Thus, they may be crucial vehicles for the identification of common audiences and common relevance goals. 


\section{RESEARCH QUESTIONS}

To examine what collaborative network brokerage roles may suggest about enhancing the urban relevance of the NPS, we focused this investigation on comparisons of present, i.e., current, and potential, i.e., desired, NPS collaborative networks. Broadly speaking, this work aims to contribute understanding to areas for targeted managerial networking for enhanced relevance. In particular, our work was guided by three questions:

1. What characteristics of present NPS urban collaborative networks are common or unique across sites?

2. What characteristics of potential NPS urban collaborative networks are common or unique across sites?

3. What does the comparison of present to potential NPS urban collaborative networks suggest about areas for enhancing relevance in the sites?

\section{METHODS}

\section{Data collection}

The sites chosen for this investigation represent three levels of NPS park presence. First, in many cities, the NPS has a programmatic presence within the city and parks more than an hour's drive away; Detroit, Michigan, represents this level of presence. Second, in a subset of these cities, the NPS also has a park adjacent to the city; Tucson, Arizona, represents this level of presence. Third, in a subset of this subset of cities, the NPS also has a park within the city; Boston, Massachusetts, represents this level of presence. The NPS selected these three sites out of the 10 in its Urban Agenda for this research because of the sites' park presence diversity, geographic spread across the country, and groundwork already started with collaborative networks for relevance.

Collaborative network list generation in Detroit, Tucson, and Boston centered on a core question from the researchers: Whom have you been in contact with about the NPS Urban Agenda with the intention of enhancing relevance? Two knowledgeable and engaged NPS staff members in each city (the Urban Fellow and Site Host) supplied this list for the network analysis in spring 2016. Lists for each city were consolidated so that each organization was represented only once, i.e., duplicate contacts were merged. The level of specificity used by the NPS compilers was considered important contextual information. Therefore, some organizations might only be represented by one contact, e. g., state department of natural resources, whereas others might be represented by multiple contacts, each representing a specific office within the organization, e.g., state department of natural resources - recreation division, state department of natural resources - planning division. Henceforth, the term "organization" is used to encompass all types of contacts. The lists contained community organizations, business ventures, civic agencies, elected officials, tribal nations, and NPS parks/ programs/offices.

The list compilers also supplied attribute data for each organization/contact. Germane to this investigation was the attribute of which of the eight NPS Urban Agenda categories (NPS Stewardship Institute 2015) the compilers felt the organization best represented. Working with the compilers and their lists, "Historic Preservation" was broadened to "Cultural
Resources" to better represent the range of organizations in that category and a ninth category of "Diversity Inclusion" was created to capture organizations listed with this primary focus (Table 1). Because this typology has been used by those involved with the Urban Agenda to categorize collaborative engagements, it was important to the managerial intentions of this work that the compilers, rather than the researchers or listed organizations, provided this attribute for each organization. We relied on the list compilers to identify the Urban Agenda category that they thought best fit each organization because their perspectives drive and will continue to drive NPS relationship considerations and thus are of greater managerial utility than assessments by the researchers or listed organizations. By using an a priori typology instead of a data-driven one, we are acknowledging the utility of building upon an agency's knowledge base and known classifications. This specific typology may be unique to the NPS, but typologies are generally used by conservation agencies to examine different categories of collaborative relationships.

A quantitative network analysis activity was conducted in MaySeptember, 2016. Potential participants were contacted by email and conducted a city-specific network analysis activity via an interactive Internet-based format designed by the lead researcher, with that researcher on the phone to give directions and answer questions. Respondents were asked to indicate whether or not they had a working relationship with the other organizations identified by their Urban Fellow and Site Host. If they did not have a current relationship, they were asked to indicate "No current relationship and DO consider a potential partner" or "No current relationship and DO NOT consider a potential partner." An option was also provided for "Not familiar enough to place in any other box" if the respondent was unsure about or did not know the organization in question. The overall response rate was $93 \%$, with Detroit at $90 \%(71 / 79)$, Tucson at $94 \%(75 / 80)$, and Boston at 97\% (38/39).

\section{Data analysis}

Data were coded in a binary matrix, analyzed in UCINET 6.2, and graphed in NetDraw (Borgatti et al. 2002). "Present network" was defined as presence of a current relationship. "Potential network" was defined as all current relationships plus those in the "No current relationship and DO consider a potential partner" response box. To examine network-level characteristics, we analyzed a selection of applicable descriptive statistics for the present and potential networks in each of the three sites, i.e., six total networks. Because we used the attribute of primary Urban Agenda category (nine categories; Table 1) to categorize organizations and because our data are directed, i.e., the "fromto" in the organizations' relationships was captured, we could then correspondingly categorize brokers into one of the five G\&F brokerage roles (Table 2). We considered two types of triads and the directionality of relationships within them in this investigation. Intransitive two-path triads are L-shaped, with one source, broker, and recipient and no direct relationship between source and recipient. Transitive triads are closed, with potentially multiple sources, brokers, and/or recipients because of direct relationships among all three. We included these transitive triads to not exclude any brokers based on the relationships between their source and recipient. Henceforth, "triad" refers to these two types considered. 
G\&F brokerage roles are determined at the triad level. In this examination, to extrapolate to the category level of the six networks (present and potential for the three sites), we determined the average number of each of the five G\&F brokerage roles for each Urban Agenda category. This average was calculated by dividing a category's total number of role-specific triads by the number of member organizations. This also helped account for the disparate sizes of category membership. For this comparison, we examined the difference between average present and potential $\mathrm{G} \& \mathrm{~F}$ brokerage role values for each category. In this manner, we report the percent capacity of each present network as a ratio of its potential network. Higher percent capacities indicate that more of the desired connections have already been made whereas lower percent capacities indicate that there is relatively more room for relationship growth.

\section{RESULTS}

\section{Characteristics of present and potential networks}

Collaborative network lists compiled by the NPS varied in their composition across the three sites (Table 3 ). Sustainability was prominent in all three sites and Cultural Resources and Outdoor Recreation were each prominent in two of the three sites. In Detroit, the largest group was Sustainability (20.3\%), followed by Economic Vitality and Outdoor Recreation (each 17.7\%). There were no Health organizations. In Tucson, Economic Vitality accounted for $22.5 \%$ of the network, followed by Cultural Resources (18.8\%) and Sustainability (12.5\%). In Boston, Cultural Resources was the largest group (44.7\%), followed by Sustainability (18.4\%) and Outdoor Recreation (13.2\%). There were no Economic Vitality organizations. City-specific NPS priorities may have driven some of these differences, though in general the Urban Fellow and Site Host were encouraged to make broad contacts across all categories.

Table 3. National Park Service Urban Agenda organizational categories by percent $(\%)$ of collaborative network list for each site.

\begin{tabular}{lccc}
\hline \hline $\begin{array}{l}\text { Organizational } \\
\text { category }\end{array}$ & \multicolumn{3}{c}{ Site } \\
\cline { 2 - 4 } & $\begin{array}{c}\text { Detroit } \\
(\mathrm{N}=79)\end{array}$ & $\begin{array}{c}\text { Tucson } \\
(\mathrm{N}=80)\end{array}$ & $\begin{array}{c}\text { Boston } \\
(\mathrm{N}=39)\end{array}$ \\
\hline Economic vitality & 17.7 & 22.5 & $\dagger$ \\
Education & 7.6 & 11.3 & 5.3 \\
Health & $\dagger$ & 5.0 & 2.6 \\
Cultural resources & 16.5 & 18.8 & 44.7 \\
Outdoor recreation & 17.7 & 7.5 & 13.2 \\
Sustainability & 20.3 & 12.5 & 18.4 \\
Urban design & 7.6 & 7.5 & 5.3 \\
Youth & 8.9 & 5.0 & 5.3 \\
Diversity inclusion & 3.8 & 10.0 & 5.3 \\
\hline$\dagger$ No group members & & & \\
\hline
\end{tabular}

Network-level descriptive statistics showed similarities across sites, despite differences in network size and composition. These results are displayed in Table 4, and a few illustrative statistics are summarized here. Network density (proportion of possible relationships actualized) averaged $32.9-38.1 \%$ in present networks and increased to $55.5-66.1 \%$ in potential networks. The present network densities in this study are within a similar range
(27.6-41.6\%) of the three NPS National Heritage Area networks examined by Laven et al. (2010). In Detroit, each organization was connected, on average, to 25.7 others, with potential to connect to 43.3 (68\% increase), i.e., average degree. The average degree in Tucson was 30.1 (present) and 52.2 (potential; 74\% increase) and in Boston was 14.0 (present) and 24.2 (potential; 73\% increase). About half of each present network had centralization features, $i$. e., dominance of a subset of organizations as relatively more connected to the network, which decreases slightly as potential contacts are also considered. Transitivity, i.e., relationship presence and direction, ranged from $27.6-37.8 \%$ in present networks, increasing to $41.0-44.5 \%$ in potential networks. Triad proportions provide a sense of the relationship closure among the three organizations. Specific measures varied, but in general intransitive triplets represented $32.9-37.4 \%$ of triads in present networks and $47.7-52.7 \%$ of triads in potential networks, and transitive triplets represented $13.5-20.0 \%$ of triads in present networks and 36.6 $40.3 \%$ of triads in potential networks.

Table 4. Descriptive statistics for present and potential National Park Service urban collaborative networks in each site. All measures except average degree are reported on a $0-1$ scale; average degree is reported as the average number of present or potential relationships for each organization.

\begin{tabular}{|c|c|c|c|c|c|c|}
\hline \multirow[t]{2}{*}{ Measure } & \multicolumn{2}{|c|}{ Detroit } & \multicolumn{2}{|c|}{ Tucson } & \multicolumn{2}{|c|}{ Boston } \\
\hline & Present & Potential & Present & Potential & Present & Potential \\
\hline Density & 0.329 & 0.555 & 0.381 & 0.661 & 0.378 & 0.654 \\
\hline Average degree & 25.696 & 43.266 & 30.087 & 52.213 & 13.974 & 24.211 \\
\hline Degree centralization & 0.517 & 0.457 & 0.505 & 0.348 & 0.486 & 0.365 \\
\hline Transitivity & 0.378 & 0.441 & 0.306 & 0.445 & 0.276 & 0.410 \\
\hline \multicolumn{7}{|l|}{ Triad proportions } \\
\hline - Empty subgraph & 0.103 & 0.012 & 0.100 & 0.006 & 0.097 & 0.002 \\
\hline - Single directed edge & 0.141 & 0.039 & 0.145 & 0.024 & 0.183 & 0.022 \\
\hline - Single mutual tie & 0.097 & 0.036 & 0.129 & 0.030 & 0.156 & 0.040 \\
\hline - Out two-star & 0.105 & 0.042 & 0.063 & 0.020 & 0.040 & 0.024 \\
\hline - In two-star & 0.027 & 0.017 & 0.024 & 0.014 & 0.035 & 0.017 \\
\hline - All intransitive triplets & 0.329 & 0.477 & 0.374 & 0.503 & 0.354 & 0.527 \\
\hline -- Intransitive two path & 0.029 & 0.019 & 0.029 & 0.012 & 0.047 & 0.020 \\
\hline - All transitive triplets & 0.200 & 0.376 & 0.165 & 0.403 & 0.135 & 0.366 \\
\hline -- Complete subgraph & 0.032 & 0.147 & 0.051 & 0.232 & 0.034 & 0.162 \\
\hline
\end{tabular}

Similarities exist in the relative frequency of G\&F brokerage roles (Table 2) for each site and network (Table 5), though the actual ratios differ. The overall number of brokers increased between present and potential networks by two-and-a-half to three-fold. Overall, when ordered greatest to least, Liaisons are the most prevalent, followed by Representatives, then Gatekeepers, then Consultants, and finally Coordinators. Only Boston's present network breaks this pattern, in that Consultants are marginally less represented than Coordinators. This means that in general, brokerage roles connecting a dissimilar source and recipient are more prevalent. For each site, the proportion of Consultant and Liaison brokers increases in potential networks while the other three roles decreased slightly, indicating a shift toward more bridges between both the source and the broker and the broker and recipient.

Table 6 depicts these triads by G\&F brokerage role and organizational category for present and potential networks in the three sites. A couple key findings are highlighted here. In Detroit and Tucson, the average number of triads with a Liaison broker is 
much higher (generally two to six times higher) than any other role. A similar pattern is seen in Boston, except for Cultural Resources, where Representative brokerage is largest. In Detroit and Tucson's present and potential networks, the brokerage role with the least representation is the Coordinator (with the exception of Economic Vitality in Tucson's present network, where Consultant is lowest). Because only three of the nine categories in Boston have sufficient membership for the Coordinator role, this pattern does not generally hold here. Two of these three categories, however, do exhibit this pattern, with Cultural Resources being a notable exception across present and potential networks.

Table 5. Percent ( $\%$ ) of total brokerage for each G\&F brokerage role in present and potential National Park Service urban collaborative networks in each site.

\begin{tabular}{|c|c|c|c|c|c|c|}
\hline \multirow{3}{*}{$\begin{array}{l}\text { G\&F } \\
\text { brokerage } \\
\text { role }\end{array}$} & \multicolumn{6}{|c|}{ Site and network } \\
\hline & \multicolumn{2}{|c|}{ Detroit } & \multicolumn{2}{|c|}{ Tucson } & \multicolumn{2}{|c|}{ Boston } \\
\hline & $\begin{array}{c}\text { Present } \\
(\mathrm{N}= \\
58,546)\end{array}$ & $\begin{array}{c}\text { Potential } \\
(\mathrm{N}= \\
151,856)\end{array}$ & $\begin{array}{c}\text { Present } \\
(\mathrm{N}= \\
78,807)\end{array}$ & $\begin{array}{c}\text { Potential } \\
\quad(\mathrm{N}= \\
218,993)\end{array}$ & $\begin{array}{c}\text { Present } \\
(\mathrm{N}= \\
7402)\end{array}$ & $\begin{array}{c}\text { Potential } \\
(\mathrm{N}= \\
21,448)\end{array}$ \\
\hline Coordinator & 4.1 & 2.9 & 4.6 & 2.7 & 13.7 & 11.4 \\
\hline Gatekeeper & 15.2 & 13.7 & 14.8 & 12.8 & 16.6 & 16.3 \\
\hline Representative & 16.0 & 14.2 & 14.8 & 12.3 & 19.9 & 17.8 \\
\hline Consultant & 11.3 & 11.5 & 10.4 & 10.8 & 12.9 & 14.3 \\
\hline Liaison & 53.4 & 57.7 & 55.4 & 61.4 & 36.9 & 40.2 \\
\hline
\end{tabular}

\section{Comparison of present and potential networks}

Table 7 lists the ratio of triads for each brokerage role in each site in present to potential networks to examine the percent capacity of the present networks, i.e., the proportion of desired relationships that have already been formed. A high percentage indicates that there are few to no additional relationships possible for a category, i.e., low growth potential, whereas a low percentage indicates many additional relationships possible for that category, i.e., high growth potential. To facilitate interpretation, this summary discusses the results in terms of quartiles of percent capacity. In Detroit, the lowest $(\leq 25 \%)$ percent capacities are in all brokerage roles for Diversity Inclusion. In Tucson, the lowest percent capacities are also in Diversity Inclusion brokers, with the addition of Coordinator, Gatekeeper, and Representative roles for Urban Design. In Boston, the lowest percent capacities are in the Consultant and Liaison roles rather than in particular organizational categories. The majority of brokerage roles are at medium-low (26-50\%) percent capacities in all three sites, with Detroit's Economic Vitality, Tucson's Education and Cultural Resources, and Boston's Cultural Resources characterized exclusively by this range. Medium-high $(51-75 \%)$ and high $(\geq$ $76 \%$ ) percent capacities in Detroit appear across most organizational categories' Coordinator roles and into others for Education, Sustainability, and Urban Design. In Tucson, these medium-high and high percent capacities also appear most frequently in the Coordinator role across organizational categories, and into others for Economic Vitality, Health, and Youth. In Boston, where most categories comprise one or two members, medium-high and high percent capacities are seen in
Gatekeeper and Representative roles and, notably, for all Outdoor Recreation brokerage roles. Figures 1 (Detroit), 2 (Tucson), and 3 (Boston) illustrate each site's present network and distribution of percent capacity quartiles by organizational category.

Fig. 2. National Park Service present urban collaborative network in Tucson. Actors colored by organizational category and sized by quartiles of percent capacity of all G\&F brokerage roles, with larger actors representing lower percent capacity and more potential for brokerage.

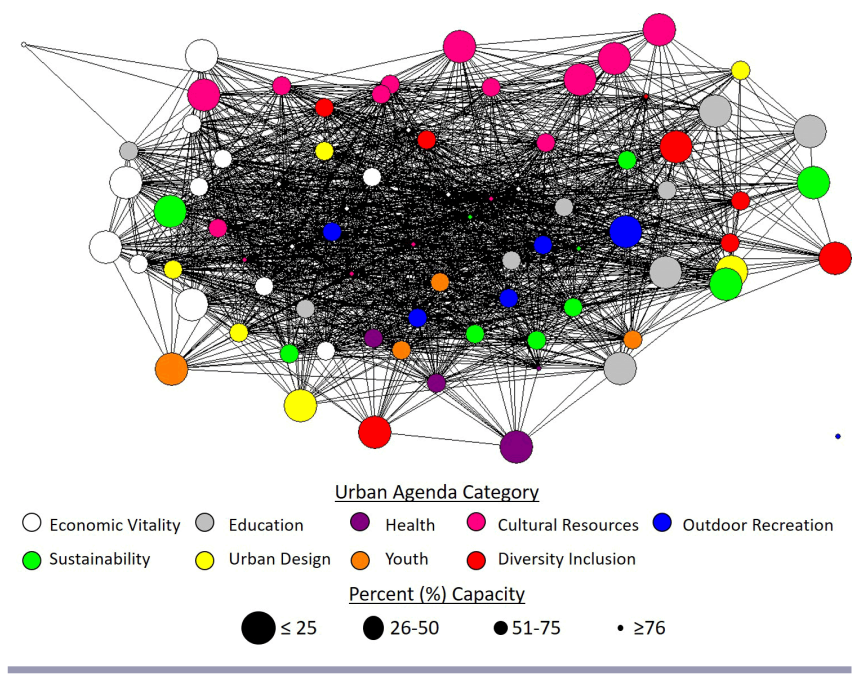

Fig. 3. National Park Service present urban collaborative network in Boston. Actors colored by organizational category and sized by quartiles of percent capacity of all G\&F brokerage roles, with larger actors representing lower percent capacity and more potential for brokerage.

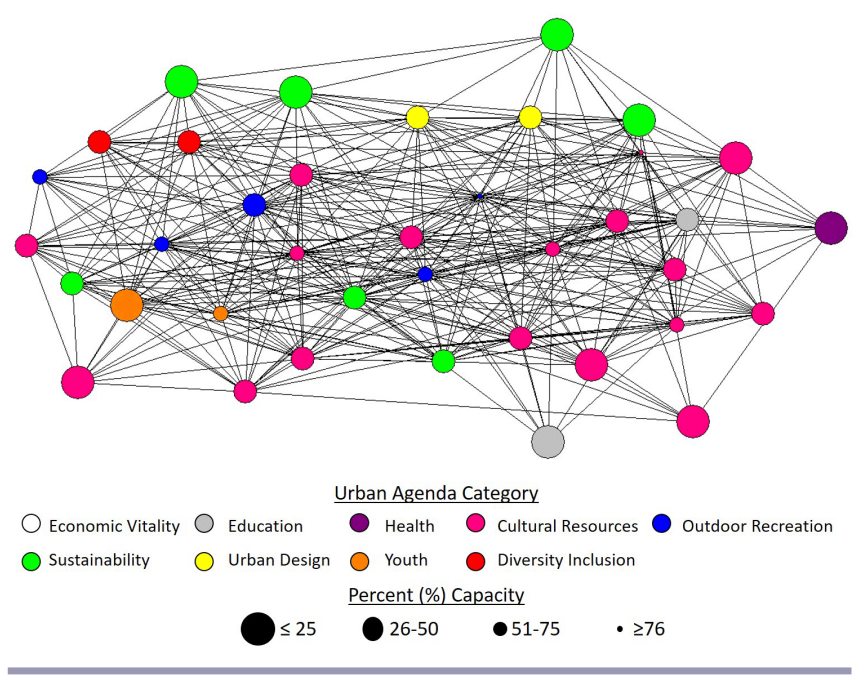

\section{DISCUSSION}

Our investigation focused on brokerage roles aggregated at the organizational category level. In this way, we have detailed group characteristics that may promote connections to diverse partners, 
Table 6. Average number of triads in each G\&F brokerage role by organizational category in present and potential National Park Service urban collaborative networks in each site.

\begin{tabular}{|c|c|c|c|c|c|c|c|c|c|c|}
\hline \multirow{2}{*}{$\begin{array}{l}\text { Site } \\
\text { and } \\
\text { network }\end{array}$} & \multirow{2}{*}{$\begin{array}{l}\text { G\&F } \\
\text { brokerage role }\end{array}$} & \multicolumn{9}{|c|}{ Organizational category } \\
\hline & & $\begin{array}{l}\text { Cultural } \\
\text { Resources }\end{array}$ & $\begin{array}{l}\text { Diversity } \\
\text { Inclusion }\end{array}$ & $\begin{array}{c}\text { Economic } \\
\text { Vitality }\end{array}$ & Education & Health & $\begin{array}{l}\text { Outdoor } \\
\text { Recreation }\end{array}$ & Sustainability & $\begin{array}{l}\text { Urban } \\
\text { Design }\end{array}$ & Youth \\
\hline \multicolumn{11}{|l|}{ Detroit } \\
\hline & Coordinator & 54.7 & 0.3 & 22.8 & 5.2 & $\dagger$ & 46.4 & 35.8 & 4.5 & 11.0 \\
\hline \multicolumn{11}{|c|}{ Present } \\
\hline & Gatekeeper & 110.6 & 20.3 & 114.0 & 80.7 & $\dagger$ & 172.1 & 118.2 & 90.3 & 65.3 \\
\hline & Representative & 213.0 & 14.7 & 65.9 & 52.3 & $\dagger$ & 161.5 & 136.1 & 54.5 & 75.1 \\
\hline & Consultant & 84.2 & 65.0 & 52.3 & 90.8 & $\dagger$ & 107.7 & 76.6 & 156.3 & 59.1 \\
\hline & Liaison & 373.0 & 411.3 & 259.9 & 526.2 & $\dagger$ & 472.5 & 338.6 & 717.8 & 295.3 \\
\hline & Coordinator & 98.7 & 2.0 & 50.8 & 7.8 & $\dagger$ & 90.0 & 59.7 & 8.8 & 17.7 \\
\hline \multicolumn{11}{|c|}{$\begin{array}{l}\text { Potent- } \\
\text { ial }\end{array}$} \\
\hline & Gatekeeper & 304.1 & 80.0 & 275.7 & 139.7 & $\dagger$ & 380.6 & 282.5 & 161.2 & 164.7 \\
\hline & Representative & 456.2 & 90.7 & 228.0 & 96.7 & $\dagger$ & 416.3 & 241.6 & 124.3 & 166.3 \\
\hline & Consultant & 217.2 & 275.3 & 177.4 & 215.8 & $\dagger$ & 273.1 & 176.3 & 312.7 & 209.7 \\
\hline & Liaison & 1082.5 & 1535.7 & 945.5 & 1174.7 & $\dagger$ & 1332.0 & 853.1 & 1487.0 & 1053.7 \\
\hline \multirow{5}{*}{$\begin{array}{l}\text { T- Pre- } \\
\text { uc-sent } \\
\text { son }\end{array}$} & Coordinator & 45.5 & 5.0 & 133.3 & 10.2 & 6.0 & 7.0 & 30.9 & 0.7 & 4.3 \\
\hline & Gatekeeper & 163.5 & 44.4 & 280.7 & 80.3 & 60.8 & 108.5 & 172.3 & 26.5 & 68.5 \\
\hline & Representative & 140.1 & 40.3 & 293.7 & 111.1 & 69.8 & 92.7 & 167.1 & 24.2 & 70.0 \\
\hline & Consultant & 94.3 & 53.8 & 89.5 & 114.8 & 68.5 & 170.3 & 129.1 & 117.0 & 119.5 \\
\hline & Liaison & 417.3 & 267.6 & 531.7 & 657.9 & 459.0 & 896.7 & 710.8 & 482.7 & 639.0 \\
\hline \multirow{5}{*}{$\begin{array}{l}\text { Pot- } \\
\text { ent- } \\
\text { ial }\end{array}$} & Coordinator & 99.3 & 22.6 & 179.0 & 27.6 & 6.0 & 11.3 & 52.5 & 5.2 & 5.0 \\
\hline & Gatekeeper & 483.3 & 169.8 & 575.2 & 240.4 & 114.0 & 230.8 & 400.2 & 110.2 & 125.0 \\
\hline & Representative & 389.7 & 247.8 & 563.2 & 292.4 & 131.3 & 188.7 & 338.5 & 129.2 & 146.0 \\
\hline & Consultant & 276.1 & 246.1 & 236.9 & 323.4 & 248.5 & 435.8 & 359.0 & 311.2 & 341.0 \\
\hline & Liaison & 1475.7 & 1372.6 & 1463.8 & 1874.3 & 1500.5 & 2476.0 & 1919.6 & 1617.7 & 2062.3 \\
\hline \multirow{5}{*}{$\begin{array}{l}\text { B- Pre- } \\
\text { os-sent } \\
\text { ton }\end{array}$} & Coordinator & 56.1 & 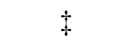 & $\dagger$ & $\ddagger$ & $\ddagger$ & 5.6 & 5.0 & + & $\ddagger$ \\
\hline & Gatekeeper & 44.7 & 10.5 & $\dagger$ & 2.5 & $\S$ & 42.4 & 26.1 & 7.5 & 15.5 \\
\hline & Representative & 59.8 & 10.5 & $\dagger$ & 7.0 & $\S$ & 42.8 & 25.1 & 2.5 & 12.5 \\
\hline & Consultant & 7.1 & 18.0 & $\dagger$ & 50.5 & 9.0 & 68.4 & 26.6 & 33.5 & 45.5 \\
\hline & Liaison & 34.6 & 87.5 & $\dagger$ & 77.0 & 29.0 & 167.4 & 69.4 & 90.5 & 142.5 \\
\hline \multirow{5}{*}{$\begin{array}{l}\text { Pot- } \\
\text { ent- } \\
\text { ial }\end{array}$} & Coordinator & 135.8 & $\$$ & $\dagger$ & $\$$ & $t$ & 5.6 & 17.0 & $\ddagger$ & $\ddagger$ \\
\hline & Gatekeeper & 142.4 & 17.5 & $\dagger$ & 22.0 & $\S$ & 64.8 & 85.6 & 12.0 & 28.0 \\
\hline & Representative & 159.9 & 22.0 & $\dagger$ & 20.0 & $\S$ & 52.6 & 98.0 & 5.5 & 24.0 \\
\hline & Consultant & 27.4 & 76.0 & $\dagger$ & 146.0 & 58.0 & 132.6 & 122.7 & 127.5 & 160.5 \\
\hline & Liaison & 122.5 & 292.0 & $\dagger$ & 312.0 & 192.0 & 314.4 & 281.3 & 303.0 & 492.0 \\
\hline
\end{tabular}

$\dagger$ No group members;

\$ Group of $\leq 2$ members cannot be Coordinators;

§Group of 1 member cannot be Gatekeepers or Representatives

ideas, and audiences and thus enhance the relevance of NPS urban networks. Prell et al. (2010) found in their work that informal structures-who regularly speaks to whom-were more explanatory of perspective on park management than other attributes such as organizational category. Our approach delves into this notion of informal structure through brokerage roles and their links to relevance while also recognizing that organizational category is a practical means of assessing the cityscape composition.
Our results suggest that there is opportunity to enhance the NPS' relevance by both capitalizing on present relationships within and among Urban Agenda categories and targeting efforts for facilitating more relationships. By acknowledging present network structure and considering which organizational categories are represented across the collaborative networks, the NPS can tailor communications and outreach efforts to complement missions of these organizations and thus aim toward common relevance goals. In this respect, our results corroborate the findings of Laven et al. (2010) examining points of entry for 
Table 7. Percent capacity (\%) in G\&F brokerage roles for each organizational category in National Park Service urban collaborative networks in each site. Percent capacity reports the proportion of present to potential triads for each organizational category and G\&F brokerage role in each site listed in Table 6.

\begin{tabular}{|c|c|c|c|c|c|c|c|c|c|c|}
\hline \multirow[t]{2}{*}{ Site } & \multirow{2}{*}{$\begin{array}{l}\mathrm{G \& F} \\
\text { brokerage role }\end{array}$} & \multicolumn{9}{|c|}{ Organizational category } \\
\hline & & $\begin{array}{c}\text { Cultural } \\
\text { Resources }\end{array}$ & $\begin{array}{l}\text { Diversity } \\
\text { Inclusion }\end{array}$ & $\begin{array}{c}\text { Economic } \\
\text { Vitality }\end{array}$ & Education & Health & $\begin{array}{c}\text { Outdoor } \\
\text { Recreation }\end{array}$ & Sustainability & $\begin{array}{l}\text { Urban } \\
\text { Design }\end{array}$ & Youth \\
\hline \multirow{5}{*}{$\begin{array}{l}\text { De- } \\
\text { troit }\end{array}$} & Coordinator & 55.4 & 16.7 & 44.9 & 66.0 & $\dagger$ & 51.6 & 60.0 & 50.9 & 62.1 \\
\hline & Gatekeeper & 36.4 & 25.4 & 41.3 & 57.8 & $\dagger$ & 45.2 & 41.8 & 56.0 & 39.6 \\
\hline & Representative & 46.7 & 16.2 & 28.9 & 54.1 & $\dagger$ & 38.8 & 56.3 & 43.8 & 45.2 \\
\hline & Consultant & 38.8 & 23.6 & 29.5 & 42.1 & $\dagger$ & 39.4 & 43.4 & 50.0 & 28.2 \\
\hline & Liaison & 34.5 & 26.8 & 27.5 & 44.8 & $\dagger$ & 35.5 & 39.7 & 48.3 & 28.0 \\
\hline \multirow{5}{*}{$\begin{array}{l}\text { Tu- } \\
\text { cson }\end{array}$} & Coordinator & 45.9 & 22.1 & 74.5 & 37.1 & 100.0 & 61.8 & 58.9 & 12.9 & 85.0 \\
\hline & Gatekeeper & 33.8 & 26.1 & 78.8 & 33.4 & 53.3 & 47.0 & 43.1 & 24.1 & 54.8 \\
\hline & Representative & 36.0 & 16.2 & 52.1 & 38.0 & 53.1 & 49.1 & 49.4 & 18.7 & 47.9 \\
\hline & Consultant & 34.1 & 21.8 & 37.8 & 35.5 & 27.6 & 39.1 & 36.0 & 37.6 & 35.0 \\
\hline & Liaison & 28.3 & 19.5 & 36.3 & 35.1 & 30.6 & 36.2 & 37.0 & 29.8 & 31.0 \\
\hline \multirow{5}{*}{$\begin{array}{l}\text { Bo- } \\
\text { ston }\end{array}$} & Coordinator & 41.3 & $\ddagger$ & $\dagger$ & $\dagger$ & $\dagger$ & 100.0 & 29.4 & $\ddagger$ & $\$$ \\
\hline & Gatekeeper & 31.4 & 60.0 & $\dagger$ & 11.4 & $\S$ & 65.4 & 30.6 & 62.5 & 55.4 \\
\hline & Representative & 37.4 & 47.7 & $\dagger$ & 35.0 & $\S$ & 81.4 & 25.7 & 45.5 & 52.1 \\
\hline & Consultant & 25.8 & 23.7 & $\dagger$ & 34.6 & 15.5 & 51.6 & 21.7 & 26.3 & 28.3 \\
\hline & Liaison & 28.2 & 30.0 & $\dagger$ & 24.7 & 15.1 & 53.2 & 24.7 & 29.9 & 29.0 \\
\hline
\end{tabular}

$\dagger$ No group members;

† Group of $\leq 2$ members cannot be Coordinators;

§Group of 1 member cannot be Gatekeepers or Representatives

further collaborative networking in NPS National Heritage Areas and where the NPS can facilitate networking for sharing ideas. For example, the NPS may consider working with Cultural Resources organizations in each site to highlight ways in which they contribute to preserving past stories and enhancing current residents' local pride in place, communicating relevance through common goals. Beyond present structure, facilitating relationships among organizational categories at lower percent capacities would be a value-added contribution of the NPS to these informal networks and thus may promote the relevance of the NPS to organizations and locals alike. Specifically, targeting these categories could demonstrate the NPS' commitment to supporting collaborative efforts in each site and valuing the goals of locals represented through multiple organizations' missions and constituents. Diversity Inclusion organizations, a category generated from the Urban Fellows' work and a group relatively new to these three NPS networks, indicated across the sites that they would like to be better integrated into the extant NPS collaborative network. Therefore, this particular category may be rich for efficient use of efforts.

This investigation also suggests that network size and composition are important considerations for enabling conditions conducive to promoting relevance across collaborations. Newig et al. (2010) posit that larger networks tend to be more flexible because there is more opportunity for replacements to step in when organizations leave. In our study, we may see a difference in this flexibility with Boston as compared to Detroit and Tucson. Boston's network is about $50 \%$ smaller and has fewer members in each category. Although this could be due to differences in how the Urban Fellow and Site Host interpreted the list compilation in Boston, the similar requests and frequent contacts among the three sites suggests otherwise. Because of Boston's relatively smaller network, only three of the nine organizational categories had enough members to assess all five G\&F brokerage roles. Furthermore, the network composition was highly centralized toward Cultural Resources $(44.7 \%$ of the network's organizations). Although not uniformly high, many of the organizational categories are already at higher percent capacities. Taken together, these details of Boston's network size and composition may indicate that it is more rigid and potentially less poised to act upon broadening relevance through diverse brokerage roles and multicategory collaborations. It may therefore be warranted in Boston and in other smaller networks where comparison criteria/sites exist to place greater consideration on how strategically and sustainably increasing network size and diversifying composition may infuse collaborative relationships with greater viewpoints, audiences, and pathways toward relevance capacity-building.

This investigation suggests three ways in which differences in prevalence of brokerage roles may affect relevance-enhancing efforts of the NPS and conservation agencies more widely. Because managerial efficiency in networking and collaborative efforts is often necessary, these three ways provide targeted areas where mindful action may promote agency and network-wide relevance.

First, working with organizational categories that are presently networked to others through a variety of G\&F brokerage roles (Table 6) can effectively identify areas of enhanced impact. These organizations could be considered "creative agents." Because 
Fig. 1. National Park Service present urban collaborative network in Detroit. Actors colored by organizational category and sized by quartiles of percent capacity of all G\&F brokerage roles, with larger actors representing lower percent capacity and more potential for brokerage.

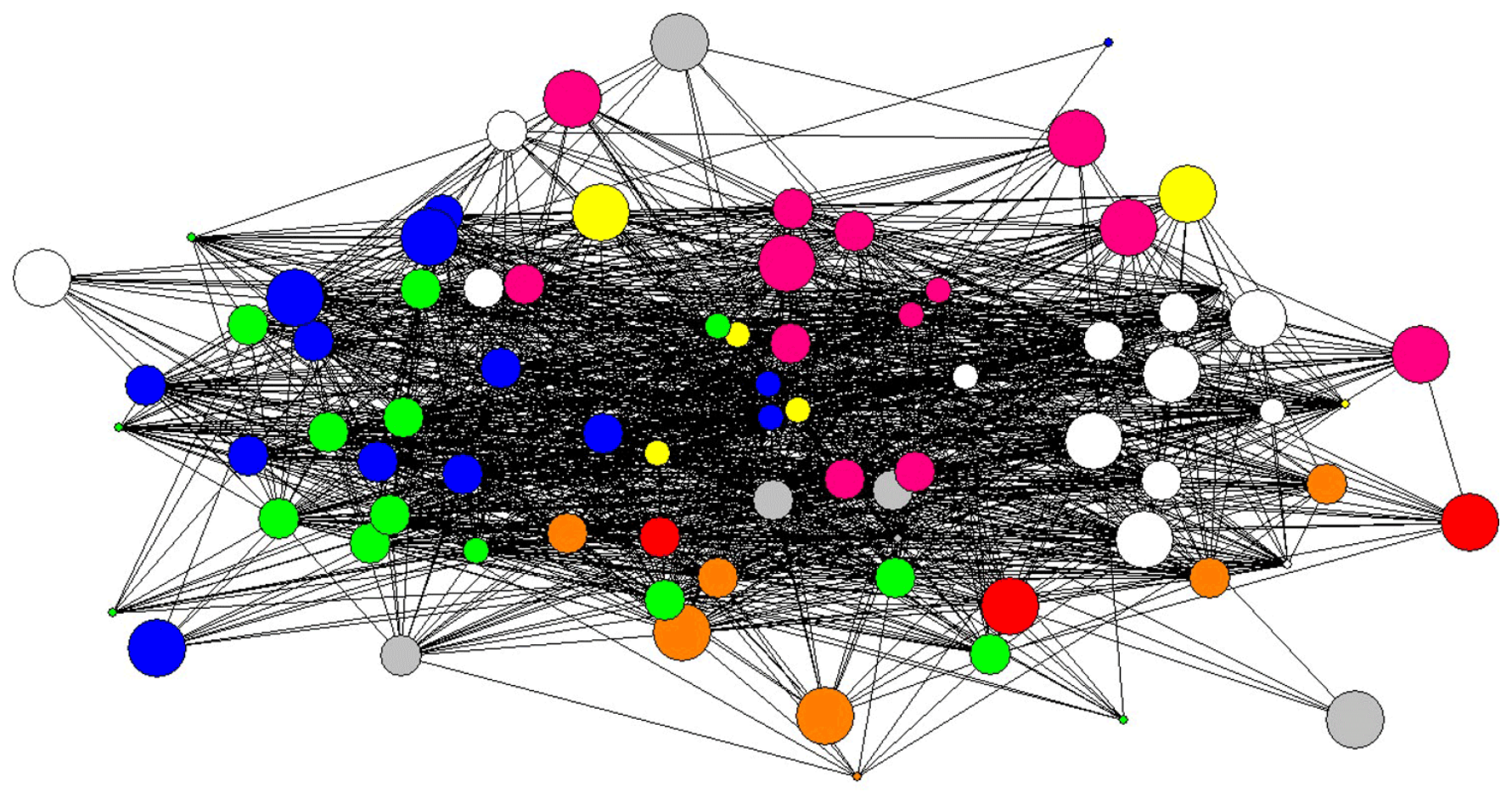

Urban Agenda Category
Economic Vitality
Education
Health
Cultural Resources
Sustainability
Urban Design
Youth
Diversity Inclusion
Percent (\%) Capacity
$\leq 25$
26-50
51-75
$\bullet \geq 76$

Outdoor Recreation

these categories exhibit flexibility in their types of relationships (within, between, and among categories), they have unique capacity to channel information among a variety of categories and thus act as creative agents who are exposed to diverse ideas on enhancing relevance. In our study, these categories are sitedependent but generally include Economic Vitality, Cultural Resources, Outdoor Recreation, and Sustainability. As also found in Ernstson et al.'s (2010) study on urban green space governance, these brokers may be seen as agents for diffuse social learning across the NPS' and others' collaborative networks. With the additional depth provided by brokerage roles, a more detailed understanding of the flexibility that brokers add to network adaptive capacity for enhancing and sustaining relevance is better understood. Our work preliminarily suggest that conservation agencies' proactively examining brokerage with the intention of preserving role diversity may enhance representation of all brokerage roles and thus opportunities for varied relevancecentered efforts.
Second, working with categories that are at relatively low percent capacities for any/all of their brokerage roles (Table 7) can focus efforts on those who have an enthusiasm for growth and those more likely to seek relationships that may broaden relevance. These categories could be considered "entrepreneurs." Some G\&F brokerage roles are currently less prominent but would be more so if potential relationships are realized. These are specific areas where the NPS and other conservation agencies may find organizations eager to widen their networks (with similar and/or dissimilar organizations) and simultaneously promote the agency's relevance across novel connections. For example, with few exceptions, the roles of Consultant and Liaison are at lower percent capacities, indicating room for growth. To foster relevance capacity-building, actionable steps may be to regularly invite one or two different groups into intra-group meetings to forge these relationships on a subnetwork level.

Third, at the nexus of these two considerations of creative agents and entrepreneurs are the subset of organizations who may 
harbor the most capacity to sustain a network for relevance: "sustainable facilitators." These are those who are currently connected across a range of brokerage roles and see potential for further connections. As Figures 1-3 depict, these individual organizations are the ones that are most central to the network structure (closest to the middle) and have the lowest percent capacity (largest organization size). This subset may be the most efficient for prioritization, to judge approaches and impacts, before the NPS and other conservation organizations would look beyond this limited subset to encourage network-wide relationships for relevance. Targeting these organizations in particular may also assist in reaching some of the other organizations and categories identified in the previous two points and thus may capitalize on a stepped approach to engagement.

The Urban Agenda efforts undertaken by the NPS are commendable but are also increasingly common across conservation agencies. Although the NPS is unique at the federal level in its dual mission of conservation and relevance, other agencies are also prioritizing collaborations for relevance as well. Our NPS-centric study in Detroit, Tucson, and Boston suggests that Urban Fellows and Site Hosts have built diverse networks with a variety of organizations that are differentially engaged with each other and may present a structure for others to consider. It also suggests that organizations that are tied to many others are probably ones that are the "usual suspects" for NPS involvement and as such may be reliable purveyors of information within and across categories. It will be important to continue to engage these groups moving forward to sustain relevance with them. However, stopping at these groups is insufficient. Organizations and categories who are currently not connected to many other NPS contacts might be groups with whom the NPS could extend its relevance mission. As with other conservation agencies' networks, these might be groups that have not been traditionally focused on in past networking and therefore not currently connected to the same network members. Undoubtedly, they have their own networks that may stretch into as-of-yet unconsidered areas of the city. Therefore, these groups may be especially good focal points for efforts to extend networks in the fringes of the agency's collaborative terrain. To do so, tailoring communications about the areas of shared goals and potential synergies is imperative. This is sometimes more difficult than with those who are in known capacity roles or with established, familiar connections to the NPS and its mission. However, if taking enhanced relevance with all Americans seriously, these are the types of community groups with which ties should be forged and deepened.

\section{LIMITATIONS}

The organizational categories used were intended to be of managerial utility. Thus, we applied categories and membership used in the Urban Agenda and by the NPS in each site. These categories are not necessarily discrete and interpretations of organizations' placement in one category may vary by list compiler or specific contact's branch/position within an organization. We did attempt to minimize this concern in our list compilation tactics by repeatedly engaging the Urban Fellow and Site Host in each site and asking them to be critical and exhaustive in their considerations. Therefore, although the investigation may differ depending on organizational category (or the use of another attribute entirely), this was the most logical and grounded approach for this research. Another issue may be with the averaging of brokerage role across a category, which may unduly give an impression of parity across a category. We assume that network-wide density measures are meaningful at the category level too, but this may require further investigation, i.e., density may impact performance differentially among categories. Inherent in this assumption is the need to further research the role of differential power among organizations and categories within an informal collaborative network. Finally, this approach may be underestimating the densities of relationships and brokerage roles because of nonrespondents. However, our high response rate indicates that the vast majority of the network's interactions were accounted for in our methods.

\section{CONCLUSION}

This investigation explored the differential prevalence of brokerage roles across present and potential NPS urban collaborative networks and what these rates may suggest about relevance capacity-building. Because relevance is a seemingly abstract, ever-over-the-horizon goal, probing brokerage as a potential indicator of it is a means to ground the concept in tangible measures. The flexibility of organizations and organizational categories to assume different types of brokerage may hint at individual and network-wide ability to enhance relevance of a conservation agency like the NPS at the center of these networks. Our work suggests that a variety of organizational categories, sufficiently sized and sufficiently diverse networks, flexibility of connection through different G\&F brokerage roles, and low to moderate percent capacities of brokerage potential may contribute to greater NPS and network relevance.

Stovel et al. (2011) contend that brokers are a fragile group because they are in demand by others but also compromised by their third-wheel presence. How, then, can brokerage be supported in ways to strengthen relevance across conservation agencies' networks? Although participants in our study were quick to recommend that a central network facilitator, i.e., the Urban Fellow, embody the role of broker leader, solutions are obviously more nuanced and dispersed. We recommend that proactively recognizing the percent capacity of brokers is one means of shoring up brokerage stability. Because percent capacity compares present and potential relationships, this method may also be both more proactive in examining relationship structures and more contextually sensitive and appropriate for directing efforts for increasing, sustaining, or paring back brokerage. These considerations may assist conservation agencies in supporting key brokers for enhancing relevance across collaborative networks and, ultimately, with diverse stewards.

\section{Responses to this article can be read online at: http://www.ecologyandsociety.org/issues/responses. php/11124}

\section{Acknowledgments:}

The authors thank the Stewardship Institute of the National Park Service and the Rubenstein School of Environment and Natural Resources at the University of Vermont for providing a research grant and doctoral fellowship, respectively, to conduct this work. 
The anonymous reviewers are thanked for their insightful feedback, which has strengthened the manuscript. The authors also express gratitude to the participants in this study for sharing their time and perspectives and to the National Park Service Urban Agenda community for their assistance and support. The lead author was at the University of Vermont when this research was conducted.

\section{LITERATURE CITED}

Aviv, R., Z. Erlich, and G. Ravid. 2005. Response neighborhoods in online learning networks: a quantitative analysis. Educational Technology \& Society 8:90-99.

Belaire, J. A., A. K. Dribin, D. P. Johnston, D. J. Lynch, and E. S. Minor. 2011. Mapping stewardship networks in urban ecosystems. Conservation Letters 4:464-473. https://doi. org/10.1111/j.1755-263X.2011.00200.X

Boari, C., and F. Riboldazzi. 2014. How knowledge brokers emerge and evolve: the role of actors' behaviour. Research Policy 43:683-695. https://doi.org/10.1016/j.respol.2014.01.007

Bodin, Ö., B. Crona, and H. Ernstson. 2006. Social networks in natural resource management: What is there to learn from a structural perspective? Ecology and Society 11(2):r2. https://doi. org/10.5751/es-01808-1102r02

Bodin, Ö., and C. Prell, editors. 2011. Social networks and natural resource management: uncovering the social fabric of environmental governance. Cambridge University Press, Cambridge, UK. https:// doi.org/10.1017/CBO9780511894985

Borgatti, S. P., M. G. Everett, and L. C. Freeman. 2002. Ucinet for Windows: software for social network analysis. Analytic Technologies, Harvard, Massachusetts, USA.

Borrás, S. 2007. The European commission as network broker. European Integration Online Papers Eiop 11.

Burt, R. S. 1997. The contingent value of social capital. Administrative Science Quarterly 42:339-365. https://doi. org/10.2307/2393923

Butts, C. T. 2008. Social network analysis: a methodological introduction. Asian Journal of Social Psychology 11:13-41. https:// doi.org/10.1111/j.1467-839X.2007.00241.X

Calvet-Mir, L., S. Maestre-Andrés, J. Molina, and J. van den Bergh. 2015. Participation in protected areas: a social network case study in Catalonia, Spain. Ecology and Society 20(4):45. https://doi.org/10.5751/ES-07989-200445

Crona, B., and Ö. Bodin. 2006. What you know is who you know? Communication patterns among resource users as a prerequisite for co-management. Ecology and Society 11(2):7. https://doi. org/10.5751/ES-01793-110207

Crona, B., and K. Hubacek. 2010. The right connections: How do social networks lubricate the machinery of natural resource governance? Ecology and Society 15(4):18. https://doi. org/10.5751/ES-03731-150418

Diamant, R. 2000. From management to stewardship: the making and remaking of the U.S. National Park System. George Wright Forum 17:31-45.

Eglene, O., S. S. Dawes, and C. A. Schneider. 2007. Authority and leadership patterns in public sector knowledge networks. American Review of Public Administration 37:91-113. https://doi. org/10.1177/0275074006290799

Enqvist, J., M. Tengö, and Ö. Bodin. 2014. Citizen networks in the Garden City: protecting urban ecosystems in rapid urbanization. Landscape and Urban Planning 130:24-35. https:// doi.org/10.1016/j.landurbplan.2014.06.007

Ernstson, H., S. Barthel, E. Andersson, and S. T. Borgström. 2010. Scale-crossing brokers and network governance of urban ecosystem services: the case of Stockholm. Ecology and Society 15(4):28. https://doi.org/10.5751/ES-03692-150428

Everett, M. G., and T. W. Valente. 2016. Bridging, brokerage and betweenness. Social Networks 44:202-208. https://doi.org/10.1016/ j.socnet.2015.09.001

Faust, K. 2010. A puzzle concerning triads in social networks: graph constraints and the triad census. Social Networks 32:221-233. https://doi.org/10.1016/j.socnet.2010.03.004

Ferreira, S. 2012. Moulding urban children towards environmental stewardship: the Table Mountain National Park experience. Environmental Education Research 18:251-270. https://doi.org/10.1080/13504622.2011.622838

Francisco Cárcamo, P., R. Garay-Flühmann, and C. F. Gaymer. 2014. Collaboration and knowledge networks in coastal resources management: how critical stakeholders interact for multiple-use marine protected area implementation. Ocean \& Coastal Management 91:5-16. https://doi.org/10.1016/j.ocecoaman.2014.01.007

Giuffre, K. 2013. Communities and networks: using social network analysis to rethink urban and community studies. Polity Press, Cambridge, UK.

Gorayska, B., and R. Lindsay. 1993. The roots of relevance. Journal of Pragmatics 19:301-323. https://doi.org/10.1016/0378-2166 (93)90091-3

Gould, R. V., and R. M. Fernandez. 1989. Structures of mediation: a formal approach to brokerage in transaction networks. Sociological Methodology 19:89-126. https://doi. org/10.2307/270949

Hamin, E. M. 2001. The US National Park Service's partnership parks: collaborative responses to middle landscapes. Land Use Policy 18:123-135. https://doi.org/10.1016/S0264-8377(01)00006-0

Harris, J. K. 2014. An introduction to exponential random graph modeling. SAGE, Los Angeles, California, USA. https://doi. org/10.4135/9781452270135

Henderson, K. A., and G. J. Walker. 2014. Ethnic and racial research methods. Pages 21-36 in M. Stodolska, K. J. Shinew, M. F. Floyd, and G. J. Walker, editors. Race, ethnicity, and leisure: perspectives on research, theory, and practice. Human Kinetics, Champaign, Illinois, USA.

Hirschi, C. 2010. Strengthening regional cohesion: collaborative networks and sustainable development in Swiss rural areas. Ecology and Society 15(4):16. https://doi.org/10.5751/ES-03714-150416

Holman, N. 2008. Community participation: using social network analysis to improve developmental benefits. Environment and Planning C: Government and Policy 26:525-543. https://doi. 


\section{org/10.1068/c0719p}

Jarvis, J. 2012. The relevance of national parks. Pages 155-159 in $\mathrm{S}$. Weber, editor. Rethinking protected areas in a changing world: Proceedings of the 2011 George Wright Society Biennial Conference on Parks, Protected Areas, and Cultural Sites. George Wright Society, Hancock, Michigan, USA.

Kalish, Y. 2008. Bridging in social networks: Who are the people in structural holes and why are they there? Asian Journal of Social Psychology 11:53-66. https://doi.org/10.1111/j.1467-839x.2007.00243. $\underline{\mathrm{x}}$

Kaźmierczak, A. 2013. The contribution of local parks to neighbourhood social ties. Landscape and Urban Planning 109:31-44. https://doi.org/10.1016/j.landurbplan.2012.05.007

Knoke, D., and S. Yang. 2008. Social network analysis. Second edition. SAGE, Thousand Oaks, California, USA. https://doi. org/10.4135/9781412985864

Laven, D. N., D. H. Krymkowski, C. L. Ventriss, R. E. Manning, and N. J. Mitchell. 2010. From partnerships to networks: new approaches for measuring U.S. National Heritage Area effectiveness. Evaluation Review 34:271-298. https://doi. org/10.1177/0193841X10370668

Long, J. C., F. C. Cunningham, and J. Braithwaite. 2013. Bridges, brokers and boundary spanners in collaborative networks: a systematic review. BMC Health Services Research 13:158. https:// doi.org/10.1186/1472-6963-13-158

Manring, S. L. 2007. Creating and managing interorganizational learning networks to achieve sustainable ecosystem management. Organization \& Environment 20:325-346. https://doi. org/10.1177/1086026607305738

McCown, R. S., D. Laven, R. Manning, and N. Mitchell. 2012. Engaging new and diverse audiences in the national parks: an exploratory study of current knowledge and learning needs. George Wright Forum 29:272-284.

McCown, R., J. Tuxill, D. Laven, N. Mitchell, R. Manning, and J. Jewiss. 2011. Beyond outreach handbook a guide to designing effective programs to engage diverse communities. National Park Service Conservation Study Institute and the University of Vermont, Burlington, Vermont.

Mitchell, N., T. Morrison, V. Farley, and C. Walter. 2006. Keeping national parks relevant for the 21 st century. National Park Service Conservation Study Institute, Woodstock, Vermont, USA.

Newig, J., D. Günther, and C. Pahl-Wostl. 2010. Synapses in the network: learning in governance networks in the context of environmental management. Ecology and Society 15(4):24. https://doi.org/10.5751/ES-03713-150424

NPS Stewardship Institute. 2015. Urban agenda: call to action initiative. National Park Service Stewardship Institute, Washington, D.C., USA.

Page, S. B., M. M. Stone, J. M. Bryson, and B. C. Crosby. 2015. Public value creation by cross-sector collaborations: a framework and challenges of assessment. Public Administration 93:715-732. https://doi.org/10.1111/padm.12161

Prell, C., M. Reed, L. Racin, and K. Hubacek. 2010. Competing structure, competing views: the role of formal and informal social structures in shaping stakeholder perceptions. Ecology and Society 15(4):34. https://doi.org/10.5751/ES-03652-150434

Romolini, M., J. M. Grove, and D. H. Locke. 2013. Assessing and comparing relationships between urban environmental stewardship networks and land cover in Baltimore and Seattle. Landscape and Urban Planning 120:190-207. https://doi. org/10.1016/j.landurbplan.2013.08.008

Sandström, A., and C. Rova. 2010. Adaptive co-management networks: a comparative analysis of two fishery conservation areas in Sweden. Ecology and Society 15(3):14. https://doi. org/10.5751/ES-03531-150314

Scott, J. 2013. Social network analysis. Third edition. SAGE, Thousand Oaks, California, USA. https://doi.org/10.1177/0038$\underline{038588022001007}$

Spiro, E. S., R. M. Acton, and C. T. Butts. 2013. Extended structures of mediation: re-examining brokerage in dynamic networks. Social Networks 35:130-143. https://doi.org/10.1016/j. socnet.2013.02.001

Stovel, K., B. Golub, and E. M. M. Milgrom. 2011. Stabilizing brokerage. Proceedings of the National Academy of Sciences of the United States of America 108:21326-21332. https://doi. org/10.1073/pnas. 1100920108

Stovel, K., and L. Shaw. 2012. Brokerage. Annual Review of Sociology 38:139-158. https://doi.org/10.1146/annurev-soc-081309-150054

Totterdell, P., D. Holman, and A. Hukin. 2008. Social networkers: measuring and examining individual differences in propensity to connect with others. Social Networks 30:283-296. https://doi. org/10.1016/j.socnet.2008.04.003

U.S. Congress. 1916. National Park Service Organic Act. U.S. Congress, Washington, D.C., USA.

Vangen, S., and C. Huxham. 2012. The tangled web: unraveling the principle of common goals in collaborations. Journal of Public Administration Research and Theory 22:731-760. https://doi. org/10.1093/jopart/mur065 